\title{
MULTILOCULAR CYSTIC ENCEPHALOPATHY OF INFANTS
}

\author{
BY
}

\section{CROME}

\author{
From the Department of Neuropathology, Fountain Hospital, Tooting, London
}

Some of the many variants of infantile cerebral cavitation (cystencephaly) fall into morphologically classifiable groups. One of these is symmetrical multilocular cystic encephalopathy of infants, examples of which have been reported under such names as "multiple cystic softening of the brain in the newborn ", " progressive degenerative encephalopathy ", " encephaloclastic porencephaly ", " polyporencephaly", " multilocular encephalomalacia", and so on.

Such brains are usually smaller than normal and show multiple cavities in the greater part of both cerebral hemispheres. The lesions are situated mainly in the outer part of the white matter and the inner layers of the cortex, although the entire substance of the brain may be involved in some areas. The cavities are separated from each other by gliosed tissue of varying thickness and many of the cysts are traversed by fine trabeculae. The temporal lobes, below the superior temporal gyri, are often spared. The basal ganglia and all lower formations are also usually intact save for a few microscopical lesions and some secondary degeneration of the cortico-fugal tracts. Histologically, the picture is composite, presenting different stages of complete or incomplete softening and leading up to final resorption of the debris. Many of the smaller cavities are filled with fat-laden phagocytes and the latter are also scattered diffusely in the adjoining solid tissue formed mainly by varying numbers of protoplasmic and fibrous astrocytes. The pleomorphism has been usually interpreted as evidence of progressiveness. It is also compatible, however, with uneven speed of repair and resorption in different areas following upon a single attack of a non-progressive disease.

Since most of the recorded cases were infants dying in early infancy, progressiveness is difficult to establish. The clinical course is usually one of marked neonatal distress followed by failure of development, convulsions, paralysis, and difficulty in feeding. The immediate gravity of the condition leaves little room for the manifestation of any possible progressive deterioration.
No significant vascular lesions have been demonstrated in the majority of the recorded cases. Some workers, however, published a few instances of similar but, except in one case (Von Cseh, 1937), more restricted cerebral changes which were associated with marked arterial lesions of obscure origin. They referred to this arterial condition descriptively as "subendothelial proliferation of connective tissue". These recorded cases will be mentioned below.

The aetiology of the condition is obscure although some workers, following Schwartz (1924), attributed it to perinatal causes.

Its pathogenesis attracted attention on account of its close morphological similarity to swayback in $\bar{D}$ lambs (Innes and Shearer, 1940; Winkelman and Moore, 1942; Lumsden, 1950) and the bearing that this may have on human demyelinating diseases.

The purpose of this communication is to report another example of this condition following neo natal asphyxia and associated with both arterial and venous lesions.

\section{Case Report}

The birth of the patient, an only child of healthy parents, began spontaneously and at term. The first stage of labour lasted 12 hours and the second one hour, during which episiotomy was performed as the child was becoming distressed. The umbilical cord was once round the neck but did not seem to be excessively tight, and the child was in fact slipped through the loop of the cord during the process of delivery. The infant, a male, weighed $3.2 \mathrm{~kg}$., and suffered from asphyxia which was treated by intragastric oxygen, " synkavit", coramine, and artificial respiration. Breathing was established after one hour and $\mathbf{4 5}$ minutes, and six hours later he vomited some blood. The provisional diagnosis was intracranial haemorrhage possibly due to haemorrhagic disease of the newborn. He was kept in oxygen. Within two days he developed a "cerebral cry ", spasticity of the limbs, and head retraction, and was thought to be dying. $\mathrm{He}$ recovered sufficiently, however, to be discharged with the mother at 20 days. At home his feeding was difficult; he regurgitated food through the nose and failed to gain weight. At 5 weeks he was admitted to a paediatric hospital. 
At this time, and often later, he was drowsy and hypothermic $\left(93.6^{\circ} \mathrm{F}\right.$.). The head circumference measured $36.2 \mathrm{~cm}$. and the fontanelles were normal. Monilia albicans was grown from a throat swab and the urine contained many yeast-like bodies. The E.S.R. was $41 \mathrm{~mm}$. in one hour. A radiograph of the chest and long bones and the Mantoux reaction $(1: 1,000)$ were negative. After treatment with penicillin and streptomycin the temperature gradually rose to a normal level in four days. He gained some weight, the E.S.R. fell to $28 \mathrm{~mm}$. in one hour, and he was discharged after 10 days. When seen again in 10 days' time the temperature was down once more to $95^{\circ} \mathrm{F}$., and he had gained no weight. He was still drowsy, with a dry skin and oral thrush. The Hb was $67 \%$, E.S.R. $17 \mathrm{~mm}$. in one hour, and the W.B.C. 16,000 , with a normal differential count. He continued to be difficult to feed, and cried weakly and hoarsely.

When $3 \frac{1}{2}$ months old, he was readmitted to hospital. He was then gravely ill, feeble, grossly dehydrated and cyanosed, with a temperature too low to record. Oral thrush and signs of bronchopneumonia were noted. The abdomen was protuberant, and the liver and spleen palpable $2.5 \mathrm{~cm}$. below the costal margin. The $\mathrm{Hb}$ was $63 \%$, the cerebrospinal fluid contained 90 R.B.C.s and 9 W.B.C.s, $40 \mathrm{mg}$. of protein and $63.5 \mathrm{mg}$. of sugar per $100 \mathrm{ml}$. The serum sodium level was $315 \mathrm{mg} . / 100 \mathrm{ml}$., potassium $22 \mathrm{mg} . / 100 \mathrm{ml}$., and urea $20 \mathrm{mg} . / 100 \mathrm{ml}$. He was placed in an oxygen tent and given antibiotics and saline. In spite of treatment his condition soon deteriorated and he died in a few days.

\section{Pathological Findings}

The available post-mortem notes mention severe bilateral confluent bronchopneumonia and enlargement of the cervical glands, some of which measured up to $1.5 \mathrm{~cm}$. in diameter. The spleen was firm, pale red, and weighed $28 \mathrm{~g}$. The liver weighed $210 \mathrm{~g}$. The anterior fontanelle was patent $(1 \times 0.7 \mathrm{~cm}$. $)$ and the posterior closed. The state of the dural venous sinuses was not recorded. Microscopy confirmed widespread bronchopneumonia, alternating with smaller areas of collapse. The enlarged cervical glands showed uniform lymphoid hyperplasia. Other somatic organs presented no noteworthy changes.

The Brain.-The brain was small, weighing $300 \mathrm{~g}$. (normal $540 \mathrm{~g}$.). This total included the cerebellum and brain-stem, which weighed $46 \mathrm{~g}$. Although fluctuant on palpation, the meninges and gyri were externally normal. Extensive bilateral and approximately symmetrical cavitation was seen in the coronal blocks of the cerebral hemispheres (Fig. 1). The cavities varied in size from about $1 \mathrm{~cm}$. in diameter to small, barely visible ones and some were obviously collapsed. Their lining was smooth, they contained clear, colourless fluid, and many were traversed by fine trabeculae, condensed in some

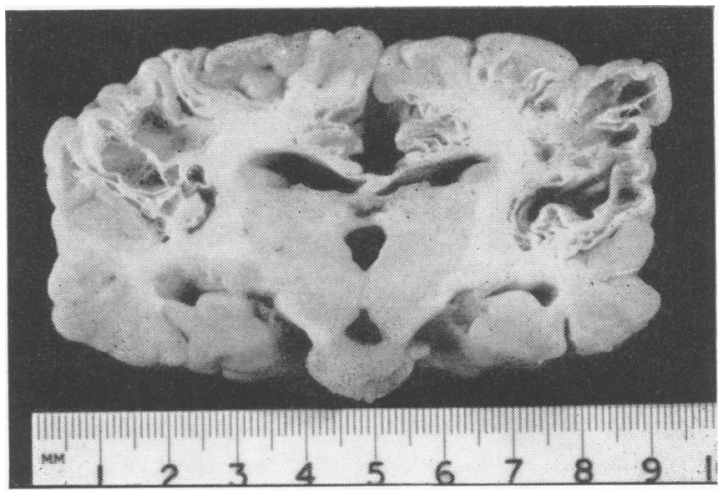

Fig. 1.-Coronal block of the brain.

areas, e.g., the insula, into a dense, spongy network. The cavities were situated mainly in the deeper parts of the cortex and subjoining white matter. The cystic change was greatest near the anterior and posterior poles of the cerebral hemispheres where the only remaining solid tissue was irregularly shaped, ragged central islands of white matter. The temporal lobes were relatively well preserved, showing some demarcation between grey and white matter, and no cavitation except in their opercular portions. Save for the claustra, the basal ganglia were also intact, although their structural details were blurred, and the tissue was abnormally firm in consistency. The corpus callosum was thin, the fornices present, and the ventricles somewhat dilated. The brain-stem and cerebellum seemed small but otherwise normal.

After prolonged fixation in formalin many coronal blocks of the cerebrum and of representative parts of the brain-stem and cerebellum were embedded in paraffin. The extracerebral radicles of the great cerebral vein were dissected and removed as they emerged under the splenium of the corpus callosum and embedded separately. Sections were stained by the customary general and neurohistological methods, and frozen material was also used for staining fat and silver impregnation.

An obvious and striking histological change was partial obstruction of vessels in the subarachnoid space by plugs or collars of connective tissue. Some of these vessels were clearly veins or arteries, but many were atypical and it was often impossible to distinguish between them. The lesions were few, affecting on the average only two or three vessels or groups of vessels in a coronal section of an entire hemisphere.

All the affected veins were situated in the upper half of the supero-lateral and medial surfaces of the hemispheres (Fig. 2). The vessels varied in calibre: the largest were medium sized and the smallest 


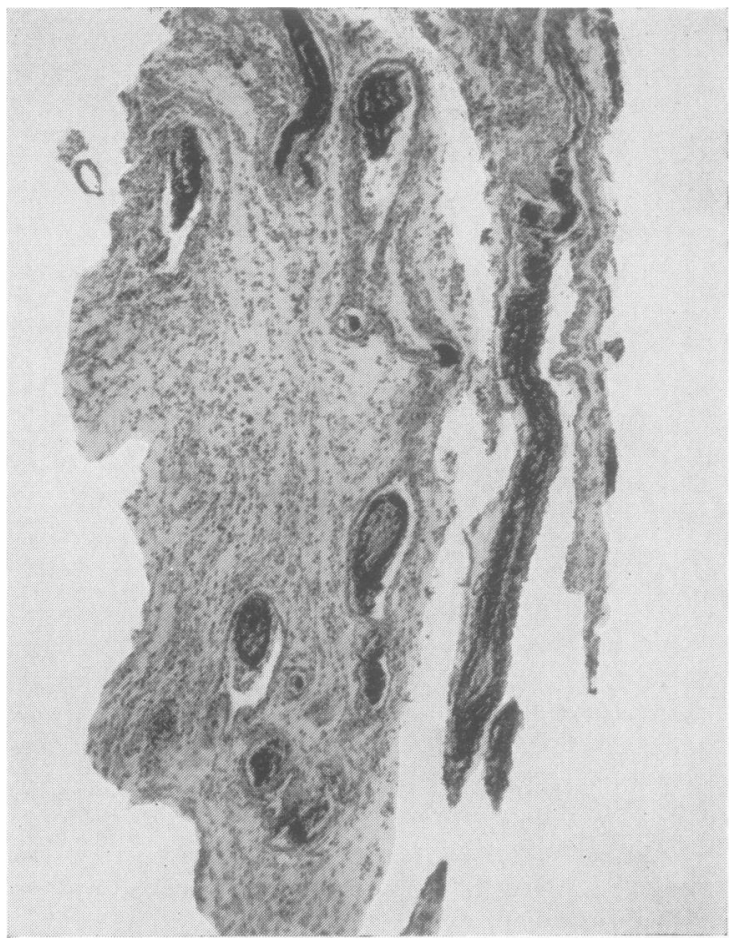

Fig. 2.-Obstructed veins in subarachnoid space. Haematoxylin and Van Gieson stain $\times 45$.

measured 50 to $60 \mu$ in diameter. While most were normally cylindrical, some showed localized dilatations with angular outlines. The occluding plugs consisted of densely arranged, parallel undulating fibres of fine collagen and reticulin with relatively few fibrocytes, and were mostly entirely or partly detached from the venous walls, thus lying freely or almost freely within the lumina of the vessels. Many contained single or multiple endotheliumlined channels (Figs. 3 and 4). A few elongated, spindle-shaped, cylindrical or polygonal particles of hyaline material, some of which showed slight peripheral calcification, were embedded in some of the fibrous plugs.

The branches of the great cerebral vein proved gritty and brittle on cutting, showing microscopically a thick, fragmented layer of hyaline partially calcified material adherent to the inner aspect of the venous wall. Where this layer was present, the remaining central part of the wall was retracted towards the lumen, thus presenting complete, or almost complete, mural reduplication. (The space between the outer and inner portion of the wall was empty and the retraction was, as in the case of the other obstructed veins, probably the result of

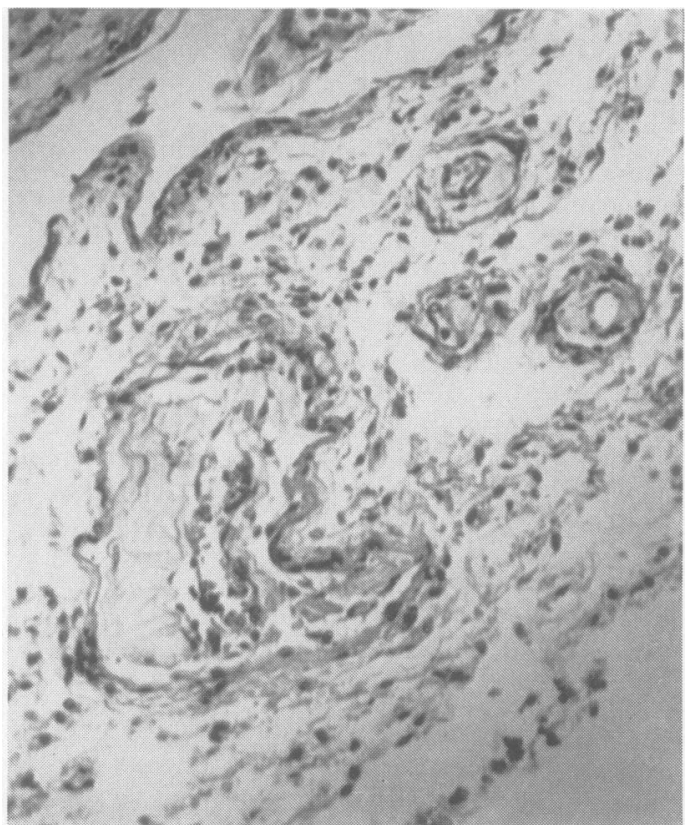

FIG. 3-Collagenized plugs with endothelium-lined spaces in veins Haematoxylin and eosin $\times 190$. recanalization. Haematoxylin and eosin $\times 190$.

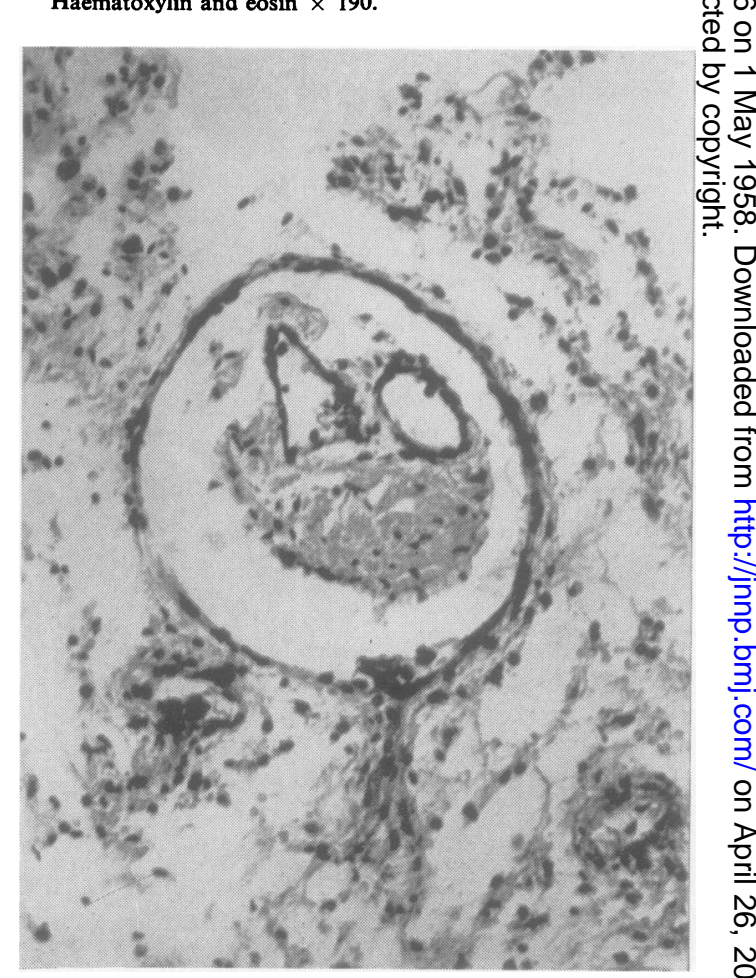

Fig. 4.-Venous plug showing retraction from vessel wall and

గ్ర 


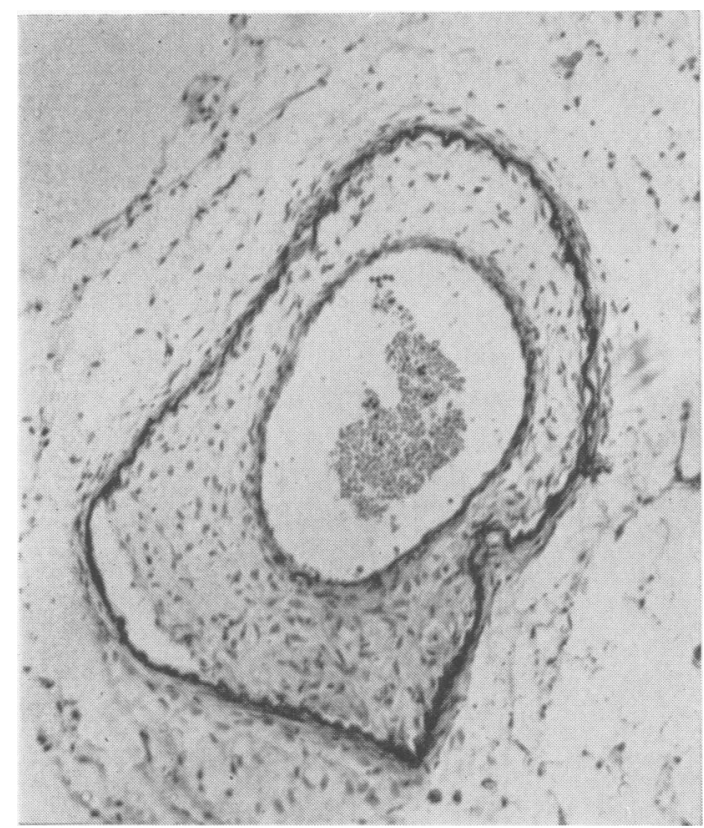

Fig. 5.-A collar of embryonic-like connective tissue in a small artery. Haematoxylin and eosin $\times 105$.

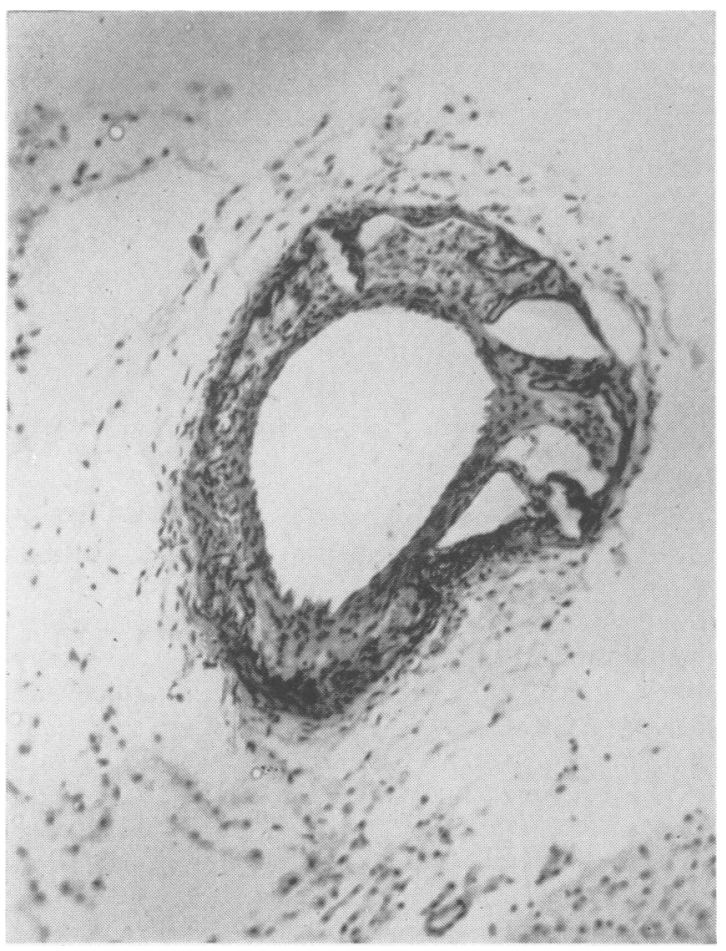

Fig. 6.-Artery showing fenestration in intramural collar of connective tissue. Haematoxylin and eosin $\times 105$. histological processing. No retraction was visible in frozen sections.) The detached inner portion of the wall was formed by connective tissue of irregular thickness and cellular density. The lumen was polygonal rather than circular in outline, retaining, however, good patency in all the sections examined.

Obstructed arteries were not as numerous as veins, but included among them a major branch of the middle cerebral artery in the Sylvian fissure. The affected arteries were identifiable by their conspicuous internal elastic laminae (Fig. 5). An annular layer of connective tissue was adherent to the inner aspect of the elastic lamina, which in some arteries showed partial calcification. Some collagen fibres were present in this tissue in the larger arteries. In others the connective tissue resembled closely embryonic mesenchyme, consisting of slender fusiform and stellate cells which formed a delicate, loose reticulum staining yellow with the Van Gieson technique and showing only a few indistinct reticulin fibres on silver impregnation by the Gordon and Sweets method. Some small granules of neutral fat were also present in this layer. Internally, around the patent lumen of the vessels, the connective tissue was condensed and collagenized in most of the affected arteries, showing also a few elastic fibres by appropriate staining. Unlike the venous plugs, the intra-arterial connective tissue showed little retraction towards the lumen, being fenestrated, however, by slit-like, empty clefts unlined by endothelium, in some of the larger vessels (Fig. 6). (This fenestration was also suggestive of the effect of histological processing on tissue of uneven density.)

Other changes in the subarachnoid space consisted of proliferation and dilatation of many of the unobstructed blood vessels. There was also focal increase of collagen and reticulin fibres with accumulation of phagocytic mononuclear cells containing neutral fat. No pigment, whether iron-containing or not, was seen in any part of the brain.

The cerebral tissue presented different stages of softening, resorption, cavitation, and gliosis. The lesions were situated under a strip of relatively well preserved cortex comprising in some areas only its outer laminae and in others its entire thickness. Whenever spared, the cortex showed only moderate astrocytic proliferation and the presence of scattered fat-laden microglial cells. Transition to the subjoining lesions was generally abrupt. These lesions consisted of cysts and solid tissue formed by varying proportions of fat-laden cells and protoplasmic and fibrous astrocytes (Fig. 7). In some areas fat-laden cells were very numerous and dense, particularly around blood vessels. In paraffinembedded material these areas resembled adipose 


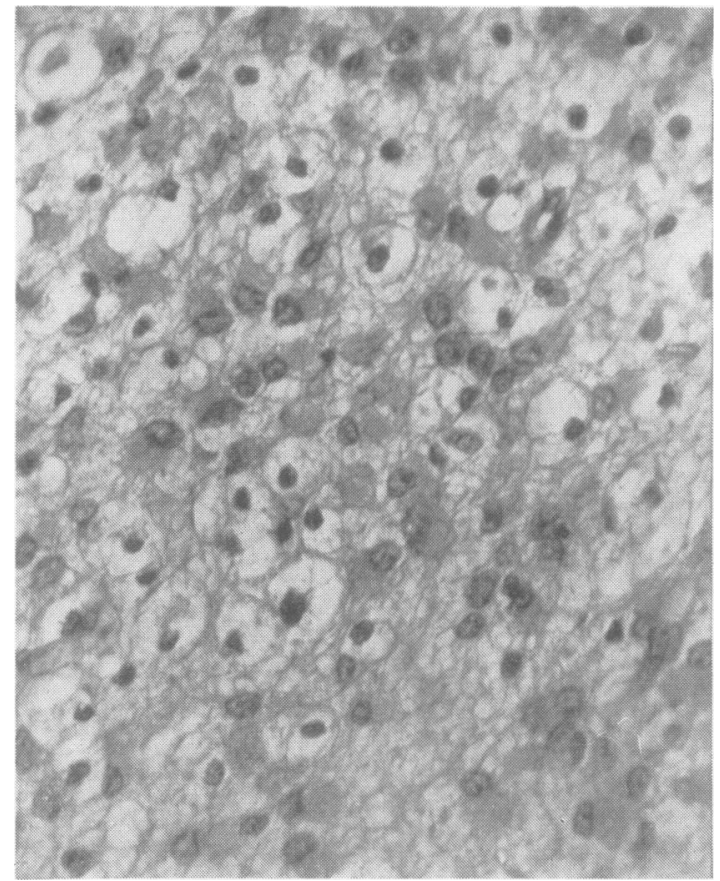

FIG. 7.-Solid tissue formed by a mixture of protoplasmic and fibrous astrocytes with many vacuolated microglial cells. Haematoxylin and $\operatorname{cosin} \times 420$.

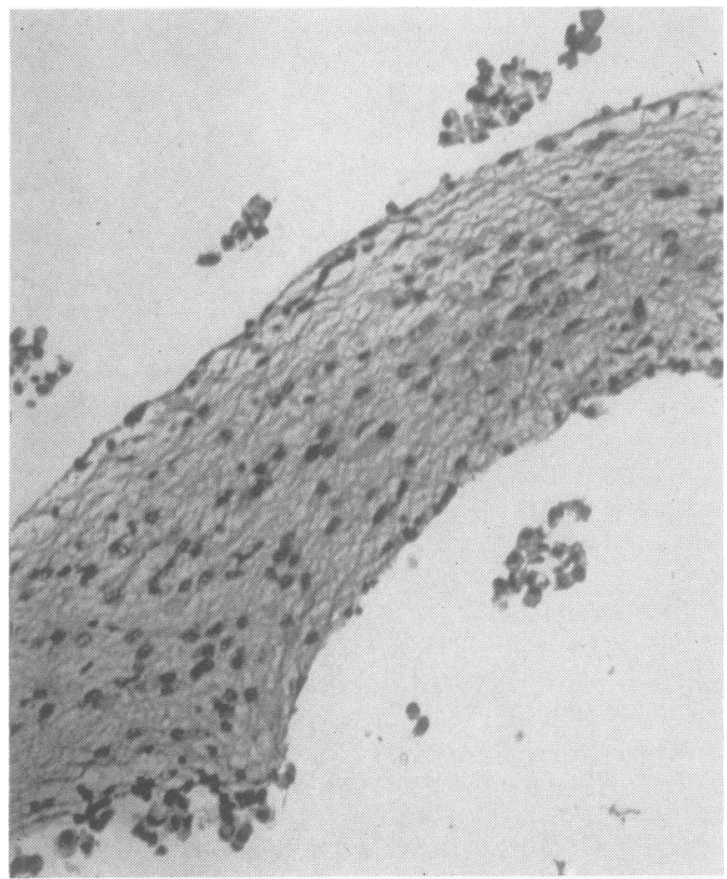

FIG. 8.-Trabeculum formed by protoplasmic and fibrous astrocytes. Phagocytic, fat-laden cells are seen in the adjoining cysts. Haematoxylin and eosin $\times 190$. tissue. They stained bright red with scarlet $\mathbf{R}$. in frozen section and contained many anisotropic crystals. In some areas protoplasmic astroyctes were more numerous, and in others, fibrous astrocytes. The cysts contained some fat-laden phagocytic cells and their trabeculae were formed by protoplasmic and fibrous astrocytes (Fig. 8).

No inflammatory change or evidence of a past or recent haemorrhage was found anywhere in the brain.

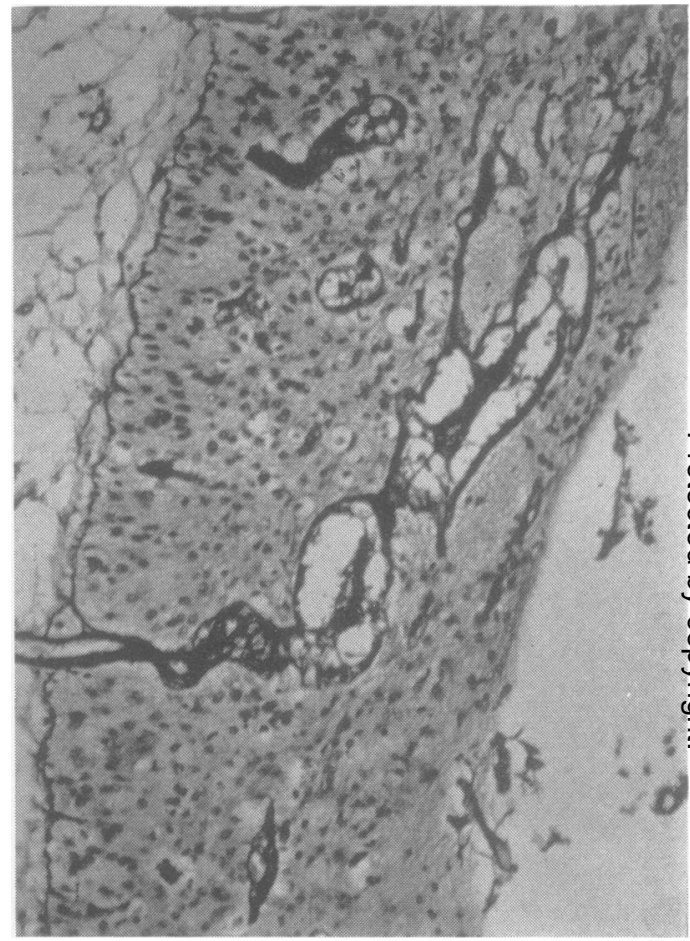

Fig. 9.-Irregularly formed intracerebral vessel. Gordon and Sweets method $\times 135$.

All intracerebral blood vessels seemed free from intramural obstruction and bore no direct evidence of past or recent thrombosis. Sections stained for reticulin showed, however, widespread focal vascular proliferation with marked irregularity of many vessels, consisting of mural duplication, localized distention, tortuosity, and thickening of their reticulin framework (Fig. 9).

With the exception of the destroyed claustra, the basal ganglia were relatively spared, showing only moderate neuronal loss with astrocytic proliferation and a few small foci of incomplete softening. Marked glial proliferation was present around the ventricles.

Few myelinated fibres could be demonstrated in and around the cerebral lesions and in the surviving 
areas of the cortex. These showed ballooning, beading, fragmentation, and unevenness of staining. Axon cylinders in Bielschowsky preparations seemed more numerous. The internal capsules were also poor in myelin fibres, but their number was greater in the lower part of the basal ganglia and in the brain-stem. The pyramidal tracts were rudimentary. Although no special study of myelination was made against normal controls, the development of tracts, other than cortico-fugal, appeared to be consistent with the age of the subject (Flechsig, 1920).

The brain-stem was substantially normal, presenting only slight diffuse and marginal astrocytic hyperplasia. The cytoarchitectonic structure of the cerebellum was also normal, but some Purkinje cells were pyknotic and shrunken. Moderate cellular and fibrous gliosis was present in the cerebellar white matter, and in this area some of the myelin fibres showed beading and fragmentation.

\section{Discussion}

Cerebral changes comparable with the above but not associated with vascular involvement have been reported by Sternberg (1930), Brocher (1932), Diamond (1934), Ford (1937), Winkelman and Moore (1942), Marburg and Casamajor (1944), Lumsden (1950), by Negrin, Lepow, and Miller (1952), and by Kramer (1956). Marburg and Casamajor thought that the condition was caused by venous thrombosis or functional "venostasis", possibly initiated by birth injury. One of their cases (Case 1) showed in fact a few venous thrombi, but these were clearly of recent antemortem origin and could not have accounted for the older cerebral lesions. Like most workers, Lumsden failed to find any vascular lesions after a careful examination of his material and birth injury was also improbable in his well documented case. He concluded that infantile encephalomalacia does not necessarily indicate past infarction but may be also the result of many other causes, such as infection, toxaemia, and degeneration. He suggested further, as a hypothesis, that important factors in the pathogenesis of the condition were the far greater degree and speed of transynaptic degeneration of infantile as compared with adult neural tissue, and its greater vulnerability to autolytic enzyme action.

Vascular lesions, arterial or venous, are, on the other hand, very familiar as an important cause of many forms of infantile cerebral cavitation and gliosis. Such lesions have been described, for example, by Byers and Hass (1933), Bailey and Hass (1937), Stevenson and McGowan (1942), Altschul (1949), and more recently by Bertrand and Bargeton (1955), Norman and Urich (1957), and Norman, Urich, and McMenemey (1957). These vascular lesions did not resemble, however, those in the present case. The patients were mostly older, cavitation and gliosis showed different localization, being also histologically more uniform in any one instance and lacking the pleomorphism of the present case.

Nevertheless, a few cases comparable with the present have been recorded. Thus in one reported by Wohlwill (1921) pial arteries showed proliferation of subendothelial connective tissue. Cavitation was confined, however, to the cerebral cortex of one hemisphere. The white matter was sclerosed but not cystic. In another case described by Levin (1936) calcification and mural thickening of pial arteries was associated with widespread and allegedly progressive multifocal softening of the cerebral cortex. Only one small cystic lesion was found in the white matter. Veins in the above two cases were intact.

Three cases reported by the Hungarian workers, Juba (1936) and Cseh (1937), bore an even greater resemblance to the present one. The brain of Juba's first case showed similar subendothelial proliferation of connective tissue in the pial arteries over both occipital lobes, the subjoining grey and white matter being the seat of "progressive" cavitation and gliosis. Juba's second case showed more widespread changes. In some vessels the subendothelial connective tissue had undergone hyaline degeneration while concentric new layers of the internal elastic lamina had been formed in a few arteries. Cseh's case was a child born after a normal confinement who developed early severe epilepsy and suffered from spastic paralysis with general retardation of development. He died aged 14 months. The brain weighed $220 \mathrm{~g}$. and showed extensive cystic degeneration in varying stages of softening, resorption, and gliosis. Changes in the pial arteries were again closely similar to those of the present case. No venous lesions were demonstrated in any of the above three cases.

In a further instance mentioned by Meyer (1948), apparently identical vascular and neural changes were found in an infant aged $3 \frac{1}{2}$ months. It is not clear from Meyer's account whether both arteries and veins were involved. The author thought that the lesions indicated preceding thrombosis. In a later joint review (Hallervorden and Meyer, 1956), the above case was referred to again, the authors stating that the commonest cause of such thrombosis was neonatal asphyxia but citing no further evidence in support of this view. This opinion was contrary to that of Juba and Cseh, who did not regard thrombosis as a possible mechanism in their cases.

Unlike the earlier cases, the present one showed a combination of both arterial and venous lesions. While it is difficult to interpret the arterial changes, 
most of the venous lesions appeared to exemplify the usual process of organization, collagenization, and recanalization of old thrombi. Since little is known about the evolution of arterial thrombotic lesions originating before or soon after birth, it would be unreasonable to exclude the possibility that both venous and arterial changes were caused in a like manner, viz., that they were thrombotic in origin.

The tentative diagnosis of haemorrhagic disease and intracranial bleeding made in this case was not substantiated by the pathological findings. It is tempting to assume a causal relationship between the neonatal asphyxia and the encephalopathy. Recognizable birth injury or neonatal distress were absent, however, in many of the previously recorded similar cases of cystic encephalomalacia with or without vascular involvement. It is also impossible to disregard their striking resemblance to swayback in lambs, which is probably of antenatal origin (Innes and Shearer, 1940).

A further problem is the disparity between the considerable extent of the neural changes and the relative sparseness of the vascular lesions. This may be explained, perhaps, by postulating the additional operation of histologically undemonstrable functional circulatory disturbances (Levin, 1936; Marburg and Casamajor, 1944) and/or the compensatory development of new vascular channels following obstruction of older ones. It is also possible that some thrombi may be resorbed without trace. Vascular lesions were, however, entirely absent in the majority of similar cases, and the reason for the cavity formation in these remained unknown. The already mentioned hypothesis of Lumsden may provide, after testing, an answer to this problem.

\section{Summary}

The brain of an infant, who had had severe neonatal asphyxia and died aged $3 \frac{1}{2}$ months, showed extensive symmetrical cystic multilocular encephalomalacia. Some of the veins of the subarachnoid space were obstructed by partially recanalized plugs of connective tissue. The main radicles of the great cerebral veins showed thickening and focal mural calcification. Some arteries in the subarachnoid space were also obstructed by an intramural collar of embryonic-like connective tissue. The literature relating to this condition is reviewed. The vascular changes were tentatively interpreted as organization of old thrombi.

I am indebted to Mr. C. L. Bourne for supplying the obstetric details of the case, to Drs. J. W. Platt and S. Yudkin for the clinical notes, and to Dr. P. W. Darby for placing the material and post-mortem notes at my disposal. Professors P. M. Daniel and C. E. Lumsden have kindly examined and discussed with me the histological sections. My colleagues at the Fountain Hospital read and criticized the manuscript of this paper.

\section{REFERENCES}

Altschul, R. (1949). J. Neuropath., 8, 204.

Bailey, O. T., and Hass, G. M. (1937). Brain, 60, 293.

Bertrand, I., and Bargeton, E. (1955). Proceedings of the Second International Congress of Neuropathology, London, 1955. Part II, p. 519. Published by Excerpta Medica Foundation, Amsterdam. Amsterdam.
Brocher, J. E. W. (1932). Z. ges. Neurol. Psychiat., 142, 107.

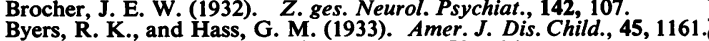
Cseh, I. von (1937). Frankfurt. Z. Path., 50, 534.

Diamond, I. B. (1934). Arch. Neurol. Psychiat. (Chicago), 31, 1153. Flechsig, P. (1920). Anatomie des menschlichen Gehirns und Rücken-

Ford, F. R. (1937). Diseases of the Nervous System in Infancy Childhood and Adolescence. p. 271. Bailliere, Tindall \&

Cox, London.
Hallervorden, J., and Meyer, J. E. (1956). Cerebrale Kinderlahmung. In Lubarsch, O., Henke, F., and Rössle, R. Handbuch derO speziellen pathologischen Anatomie und Histologie, vol. 13,

Innes, J. R. M. 262. and Shearer, G. D. (1940). J. comp. Path., 53, ban电 13 , teil 4, 1 .

Juba, A. (1936). Arch. Psychiat. Nervenkr., 104, 663.

Kramer, W. (1956). J. Neurol. Neurosurg. Psychiat., 19, 209.

Levin, P. M. (1936). Arch. Neurol. Psychiat. (Chicago), 36, 264.

Lumsden, C. E. (1950). J. Neuropath., 9, 119.

Marburg, O., and Casamajor, L. (1944). Arch. Neurol. Psychiat. (Chicago), 52, 170.

Meyer, J. E. (1948). Arch. Psychiat. Nervenkr., 180, 647.

Negrin, J., Lepow, H., and Miller, B. (1952). J.' Neuropath., 11, 62.

Norman, R. M., and Urich, H. (1957). J. Path. Bact., 73, 580.

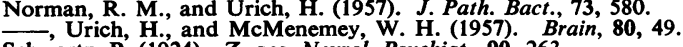

Schwartz, P. (1924). Z. ges. Neurol. Psychiat., 90, 263.

Sternberg, C. (1930). Beitr. path. Anat., 84, 521 .

Stevenson, L. D., and McGowan, L. E. (1942). Arch. Path. (Chicago), 34, 286.

Winkelman, N. W., and Moore, M. T. (1942), Arch. Neurol. Psychiat. (Chicago), 48, 54.

Wohlwill, F. (1921). Z. ges. Neurol. Psychiat., 73, 360. 